\title{
Literature Review on Disability Participation in the Engineering Field
}

\section{Elizabeth Marie Spingola, Virginia Tech Department of Engineering Education}

Liz was the first person in the nation to graduate with a B.S. in Engineering Education from Ohio Northern University with a minor in Mathematics in May, 2014. In generalities, this degree acts as a general engineering degree with a concentration in Computer Science and a Mathematics Education degree with a minor in Mathematics. With this, Liz earned her 7-12 Ohio teaching license in Mathematics. Currently, she is a graduate students at Virginia Tech where she is working on completing her Masters in Data Analytics and Applied Statistics and her $\mathrm{PhD}$ in Engineering Education surrounding computer science design standards for cognitively disabled individuals. Liz is a Graduate Assistant for the Instructional Technology Team. She provides technical support for the engineering software used by faculty and students throughout the College of Engineering including DyKnow, OneNote, Microsoft, and Inking. Additional tasks tasks include the support and editing of website content, documentation and creation of software tutorials, teaching of support classes, and support for tablet use. 


\title{
Literature Review on Disability Participation in the Engineering Field
}

\author{
Elizabeth Spingola \\ Virginia Polytechnic Institute and State University \\ lizsping@vt.edu
}

\begin{abstract}
Minority and underrepresented groups within engineering has been and still remains an increasingly studied branch of engineering education. Typically studies falling under minority and underrepresented groups focus on women, racial minorities, and, recently, the LGBTQ+ community and methodologies on how to include higher numbers of these groups within the field of engineering. However, additional minority and underrepresented groups in engineering have been researched to a lesser degree. Such groups include veterans and disabled individuals. This research systematically reviews the literature about disabled individuals' involvement in engineering. Within this literature review, disability is classified in four different groupings: physical, intellectual/cognitive, behavioral, and psychiatric. Additionally, the participation of disabled individuals is classified into different groups including: disabled student, disabled engineer, consultant, and engineered product for disabled individuals. Further, key words pertaining to stigmatized and noninclusive words describing the disabled community and disabled individuals have been counted and the occurrences per article are recorded. Finally, statistical tests were run to identify prevalent and emergent themes occurring when analyzing the participation of disabled individuals in the engineering field. A discussion of the results is presented along with potential reasoning as to why disabled individuals' involvement and participation within the engineering field remained underrepresented.
\end{abstract}

\section{Background}

Traditionally, the engineering field has comprised of mainly white, middle class, typically functioning men [1]. Through the historic integration of the civil rights movement in society starting within the 1970 s, the picture of engineering has slowly begun to change to include more racially diverse people along with women [2]. However, these populations remain underrepresented within the engineering field $[3,4]$. Only recently has there been pushes within 
the engineering field to transform the diversity of the engineering field to actively include the LGBTQ+ population and the disability community [2]. Throughout the history of engineering, the disabled community has traditionally remain as a "population" for engineers to study, "help", and "fix", rather than a population that should be recognized for their individuality and included as engineers within the field [5]. While the efforts for a broader scope of diverse inclusion in engineering remain, the rate of meaningful participation for a wide variety of disabled individuals still is relatively unexplored $[3,4]$.

This literature review systematically reviews the literature surrounding engineering, disability, use of stigmatized disability related words, and the use of disabled individuals as solely a population to study rather than active participants in the research and engineering field. It is important to note that this literature review and this research is focused on understanding the manner in which disability, the disabled community, and the disabled population is perceived, accepted, included, and integrated into the engineering scholastic field.

\section{Methods}

For this research study a systematic review of the literature was utilized. To do this, key words were identified through the exploration of disability literature. Additionally, the time frame for published literature was limited to 2013-2018 to capture the most recent literature on disability related to the engineering field and engineering research. The data was collected using Google Scholar and the ASEE conference preceding data base for the national conferences along with the key words found within Table 1. These key words were chosen by looking at societal disability research and important aspects of disability, theoretically, especially as it pertains to engineering and engineering literature. 


\begin{tabular}{|c|c|}
\hline \multicolumn{2}{|c|}{ Key words } \\
\hline Disability & Population \\
\hline Accessibility & Participation \\
\hline $\begin{array}{c}\text { Stigmatized words (stupid, } \\
\text { lame, retarded, special) }\end{array}$ & Child \\
\hline Teen & College \\
\hline K-12 & Elderly \\
\hline Education & Engineering \\
\hline Design & Technology \\
\hline
\end{tabular}

Table 1: Key words searched for within the literature review

Within Google Scholar the key words disability, accessibility, engineering, and education were used to search for articles. Each of these words was entered separately into Google Scholar. Once a promising article was identified using the key words, the citation was placed within an excel spread sheet, the article was read, and all of the key words were searched for within the articles using the search function. The number of occurrences for each of the key words was recorded within the Excel sheet after reading and understanding the surrounding context in the article to ensure the proper documentation of the words and the proper collection of the data. Finally, the same key word search process was utilized within the American Society of Engineering Education (ASEE) conference proceedings. These results were recorded in a separate Excel sheet. Only relevant and non-redundant research papers were recorded within this secondary search.

Once the data was collected, the Excel sheets were imported into Minitab to obtain descriptive statistics for both of the data set. From there, the results from both of the data sets were compared to each other to better understand ASEE as a sub set of the larger data population obtained through the use of Google Scholar. Finally, visual representations of the data were created to further understand the shape of the data sets that were collected. Due to the massive amounts of data collected, additional data analysis needs to be completed to fully understand the 
data collected in a meaningful way. In the future, ANOVA tests and multiple linear regression models will be made with the collected data to better understand the relationships between the variables and different data sets.

\section{Results}

Through the Google scholar search, 1,329 relevant papers were identified using the key words "engineering" and "disability". Out of these papers, over 800 of these articles talked about technology in correlation to disability. The least talked about were emotional disabilities while the most common disability type that was talked about was physical disabilities. Commonly, the population was disabled individuals without the participation of the disability community. Over 100 articles used words that are stigmatized within the disability community such as retarded, stupid, and lame. A summary of the frequency of Google Scholar articles incorporating the presented variables is presented within Graph 1.

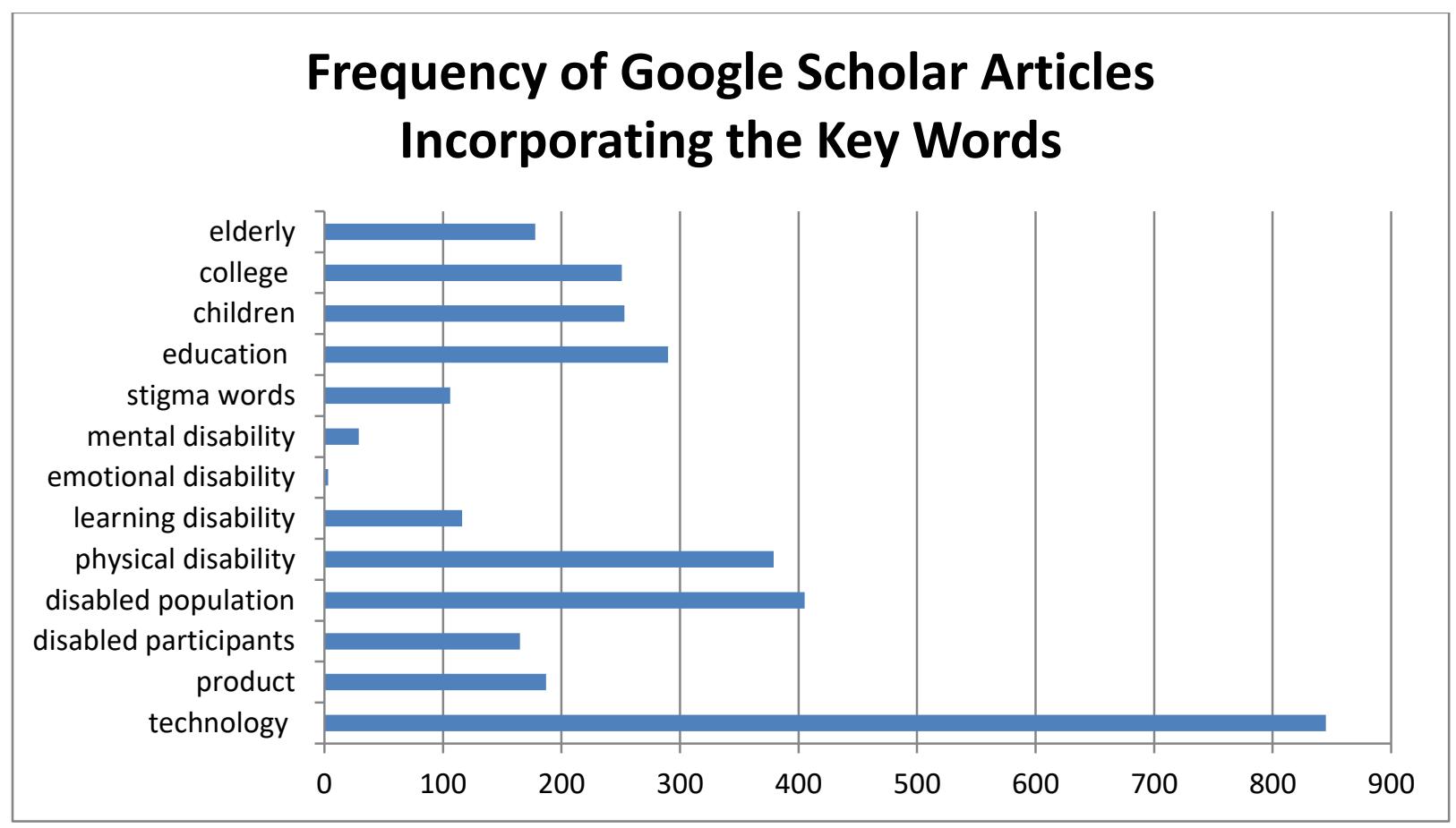

Graph 1: Frequency of Google Scholar Articles Incorporating the Presented Key Words 
Through searching within the ASEE database, 596 papers were identified using the key words "engineering" and "disability". Out of these papers, 363 focused around engineering within a college setting. Similar to the results in from Google Scholar, the least represented disability type was emotional disabilities. However, unlike the Google Scholar data, the most common disability type was learning disabilities. A more detailed and in-depth summary of the frequency of all of the variables incorporated within the ASEE papers can be found within Graph 2.

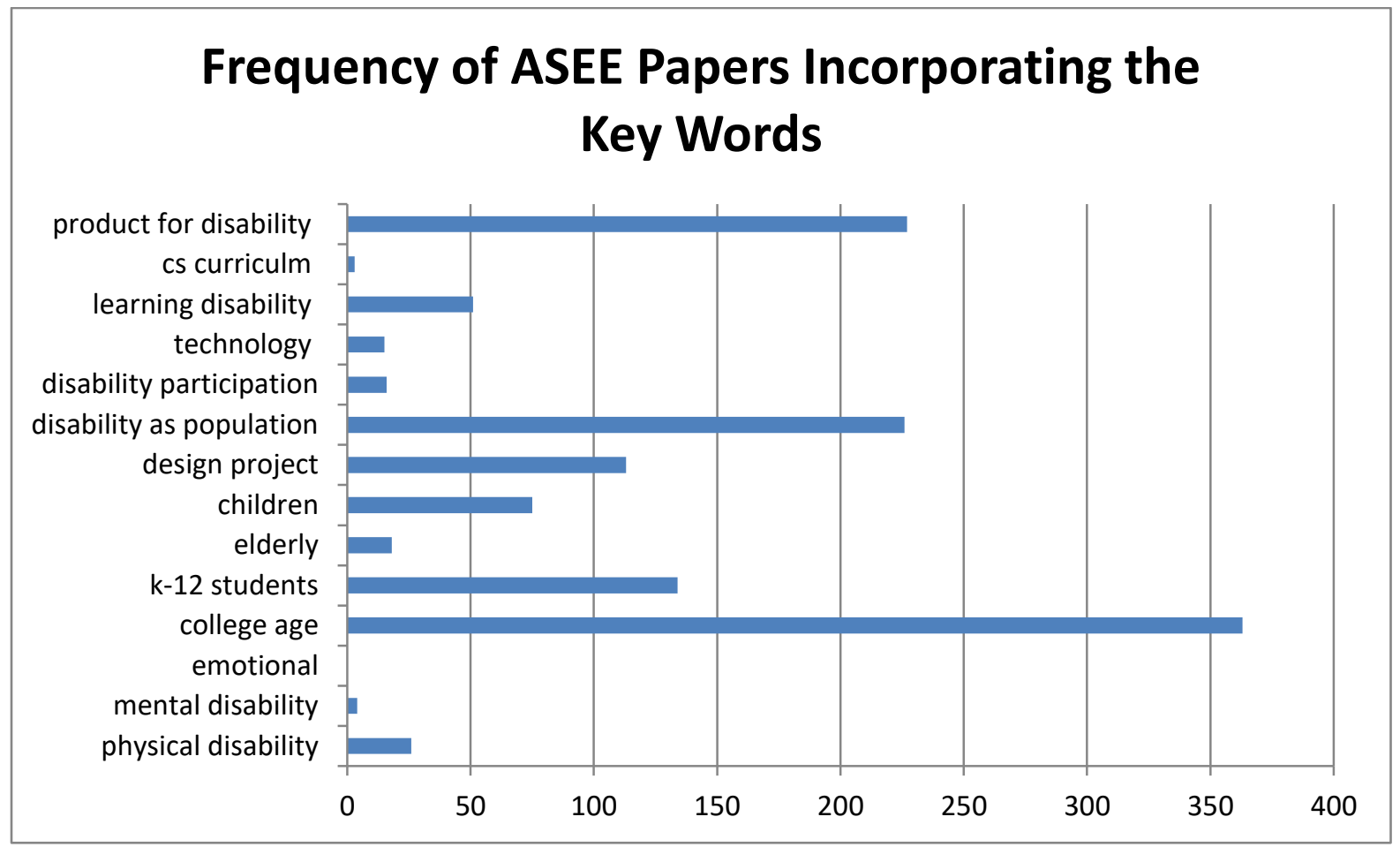

Graph 2: Frequency of ASEE Papers Incorporating Stated Key Words

\section{Discussion}

The data and the results provided supports to the idea that the inclusion of the disabled population and disabled community in a meaningful manner in engineering remains an emerging area. Through the exploration of the data is became apparent that traditional engineering still tends to view disabled people as a population and creates products to "fix" them rather than being perceived as a population that has a unique perspective and should be included and educated as an equal engineering partner. Furthermore, research on engineering education at the 
college and graduate level is minimal. Disability research ON disabled individuals primarily focuses on physical disabilities of K-12 students and the "elderly" population. This leaves a meaningful gap in the research on disability and engineering research within higher education.

These results are echoed even within the ASEE conference proceedings data set. The narrative of "design for disabled students" and "design for disabled individuals" rings loudly through this data set perpetuating the "othering" ideology of the disabled population. Within the othering ideology researchers come from the mindset of "us" versus "them", "engineers" versus "the disabled", "the included population" versus "the excluded target population". This narrative subtly speaks to the exclusion of the disabled population within engineering.

Furthermore, the low representation of engineering research related to mental, emotional, and learning disabilities within higher education denotes a gap in data collected about and with this particular subset of the disabled population. This gap was particularly noticeable within the results found within the Google scholar data. The largest discrepancy between the two data sets was the representation of learning disabilities within the literature. The ASEE data set showed a larger percentage of literature on learning disabilities than the Google Scholar data. This could be explained by the innate focus on education and learning that is present within the ASEE conferences and literature.

\section{Conclusion}

Through the exploration of the recent scholarly literature on the intersection of engineering education, engineering research, and the disabled population it is evident that there is a blatant need for more research including the perspectives of disabled individuals in both engineering education and engineering practice. Additionally, there is less data present about invisible disabilities and their intersection with the engineering field and engineering education. This data and research presents a specific need for future research in the inclusion of disabled students, individuals, and industry works within the engineering field. Further, this research presents questions about how to recruit and retain disabled individuals in engineering education within all levels of education. Finally, this research presents the idea that the depiction of 
disability within engineering has the potential to expand to include disabilities beyond physical disabilities.

\section{Future Research}

Further analysis of the data collected is needed to better understand the relationship between engineering and disability. Further research of particular interest and importance would be to investigate if there is more research on disabilities or invisible disabilities in other fields in relation to their representation within the engineering literature. Additionally, it may be informative to see if the amount or level of research on disabilities in engineering is proportional to students, practicing engineers, and engineering researchers that have a disability. With the aid of the future research on the representation of disability in engineering literature a better understanding of the perception of disabilities in engineering and the literature gaps can be made more apparent. Furthering research and understanding in this field can potentially lead to a better understanding of the recruitment and retention of disabled engineering students. 


\section{References}

1. Long, M., Steinke, J., Applegate, B., Knight Lapinski, M., Johnson, M. J., \& Ghosh, S. (2010). Portrayals of male and female scientists in television programs popular among middle school-age children. Science Communication, 32(3), 356-382.

2. Thomas, N., \& Smith, A. (2003). Preoccupied with able-bodiedness? An analysis of the British media coverage of the 2000 Paralympic Games. Adapted Physical Activity Quarterly, 20(2), 166181.

3. Hong, L., \& Page, S. E. (2004). Groups of diverse problem solvers can outperform groups of high-ability problem solvers. Proceedings of the National Academy of Sciences of the United States of America, 101(46), 16385-16389.

4. Clough, G. W. (2004). The engineer of 2020: Visions of engineering in the new century. National Academy of Engineering, Washington, DC.

5. Pope, A. M., \& Brandt Jr, E. N. (Eds.). (1997). Enabling America: Assessing the role of rehabilitation science and engineering. National Academies Press. 